\title{
Sex Differences and In-Hospital Outcomes in Patients Undergoing Mechanical Circulatory Support Implantation
}

\author{
Colleen K. Mcllvennan, DNP, ANP ${ }^{1}$, JoAnn Lindenfeld, MD², David P. Kao, MD ${ }^{1}$ \\ ${ }^{1}$ University of Colorado, School of Medicine, Division of Cardiology, Aurora, Colorado; \\ ${ }^{2}$ Vanderbilt University, School of Medicine, Division of Cardiology, Nashville, Tennessee
}

\begin{abstract}
Background: Mechanical circulatory support (MCS) is a widely available management strategy. No studies describe sex differences in both extracorporeal and durable MCS. We analyzed sexrelated differences of in-hospital outcomes for extracorporeal and durable MCS using administrative hospital data.
\end{abstract}

Methods: In total, 134.5 million hospital records between 1994-2012 were screened for placement of MCS using ICD-9 CM procedure codes. Major adverse events (MAE) were defined as death, major bleeding, stroke, device infection, or mechanical complication. Participation in the INTERMACS registry was determined on an annual basis using quarterly INTERMACS reports. Associations between characteristics and outcomes were determined using multivariable logistic regression.

Results: Sex was reported in 3,523/4,337 patients undergoing MCS placement from 45 INTERMACS sites $(\mathrm{n}=1,383)$ and 246 non-INTERMACS sites $(\mathrm{n}=2,954)$. Twenty-two percent were female. Baseline characteristics were significantly different with women being slightly younger ( $33.5 \%$ vs. $27.4 \%$ <age 50 , p $<0.001$; mean $55.7 \pm 17.3$ vs. $56.1 \pm 14.6$ years) with fewer comorbidities. Women had higher rates of in-hospital mortality $(52.3 \%$ vs. $40.8 \%, \mathrm{p}<0.001)$ and MAEs (64.8\% vs. $52.5 \%$, p $<0.001)$. Women had an $89 \%$ higher likelihood of MAE when corrected for multivariate predictors ( $\mathrm{p}<0.001$ ). In-hospital mortality decreased over time for both men and women $(10 \%$ RRR/year, $\mathrm{p}<0.001)$, but mortality in women was higher than men throughout the study period.

Conclusion: There are significant sex differences in characteristics and outcomes of patients receiving MCS. Women had higher in-hospital mortality and were at increased risk of MAEs that was not explained by age or comorbid conditions. Further research on the causes of these disproportionate outcomes is needed.

\section{Keywords}

heart-assist device; heart failure; sex; cardiac surgery

CORRESPONDING AUTHOR: Colleen K. McIlvennan, DNP, ANP, University of Colorado, School of Medicine 12631 East $17^{\text {th }}$ Avenue, B130 Aurora, CO, 80045 Phone: 920-540-0809 Fax: 303-724-2094 colleen.mcilvennan@ ucdenver.edu.

Conflict of Interest Disclosures: None. 


\section{BACKGROUND}

Mechanical circulatory support (MCS) made its initial debut in the 1950s to support cardiac surgery. $(1,2)$ Significant advances have been made since that time including the development of durable continuous-flow devices such as the HeartMate II (Thoratec, Pleasanton, CA) and HVAD (HeartWare, Framingham, MA) left ventricular assist devices (LVAD). Important sex differences in survival and outcomes have been described for other cardiac surgeries, (3-5) and the exponential rise in the use of short-term and long-term MCS in the United States emphasizes the need to track sex differences in use and outcomes.(6-8) The Interagency Registry for Mechanically Assisted Circulatory Support (INTERMACS) established in 2005 is a prospective registry that collects clinical data from pre-implant through the recipient's remaining lifespan.(9) The most recent INTERMACS statistics show that from June 23, 2006 through September 30, 2015, women accounted for 21.2\% ( $\mathrm{n}=3254)$ of all MCS.(9) While INTERMACS is an expansive repository, it relies upon voluntary hospital participation and manual data entry. Further, data only date back to 2006 when 15 hospitals participated in the registry, and a large percentage of MCS devices are placed in non-INTERMACS sites. Hospital record data have been made publically available in several states dating as far back as 1994. Herein, we report sex-related differences of both extracorporeal and durable MCS devices and associated outcomes using administrative hospital data.

\section{METHODS}

This analysis was approved via exemption by the Colorado Multiple Institutional Review Board. De-identified hospital discharge data were obtained from California (2000-2011), (10) New York (1994-2007),(11) New Jersey (1997-2011),(12) New Hampshire (19992007),(13) West Virginia (2003-2007),(14) Colorado (2006-2012)(15) and Texas (19992008).(16) We included hospital encounters that reported MCS implantation defined as International Classification of Diseases-9, Clinical Modification (ICD-9 CM) procedure codes 37.60 (simultaneous biventricular external assist device [BiVAD]), 37.62 (temporary ventricular assist device [VAD]), 37.65 (single ventricle extracorporeal VAD) or 37.66 (implantable VAD). All patient demographics and admission characteristics were determined using dataset documentation.

Hospital participation in the INTERMACS registry was determined on an annual basis using quarterly INTERMACS summary reports to identify cases reported to INTERMACS. Specifically, hospitals submitting cases to the INTERMACS registry during the $4^{\text {th }}$ quarter of a calendar year were considered to be active INTERMACS sites for that year.

INTERMACS reporting status was set as a categorical covariate in subsequent analyses.

The primary outcome for this study was a major adverse event (MAE) defined as death, significant bleeding (intracerebral hemorrhage, hemorrhagic cystitis, hematemesis, throat hemorrhage, epistaxis, gastrointestinal hemorrhage not otherwise specified, hematuria, intraperitoneal hemorrhage, or variceal bleeding), stroke, device infection or mechanical device complication. Secondary outcomes included in-hospital death, length of stay, and discharge to home versus subacute care such as skilled nursing facilities. 


\section{Statistical Analysis}

The primary covariate of interest was sex. Associations between outcomes and patient demographics, comorbidities, route of admission, year of hospitalization, acute presentation diagnoses, and INTERMACS report status were modeled using step-forward multivariable logistic regression. All patient characteristics with a chi-squared p-value $<0.05$ between patients with and without an adverse event or a Mann-Whitney U test p-value $<0.05$ for length of stay were included in univariate, then multivariable logistic regression for MAE and death and Poisson regression analysis for length of stay. A univariate $\mathrm{p}<0.05$ was used as entry criterion for multivariable analysis. Data harmonization was performed using MySQL Server (version 5.5.24, Oracle Corporation, Redwood City, CA). Statistical analyses were performed using the R statistical package (version 3.1.1, R Foundation for Statistical Computing, Vienna Austria). A p-value $<0.05$ was considered significant throughout.

\section{RESULTS}

\section{Study Population Demographic and Clinical Characteristics}

Between 1994 and 2012, 4,337 MCS events were identified from approximately 134.5 million hospital discharge records. Due to state-specific de-identification practices, sex was reported in 3,523 cases, with the majority of missing data arising from California (775/1,509 missing sex). Overall 1,383/4,337 (31.9\%) MCS procedures were performed at sites during participation in the INTERMACS registry. Trends in sex distribution of MCS are found in Figure 1. Women made up a minority (22\%) of MCS recipients throughout most of the study period with the exception of the first 2 years when procedure volume was low ( $(20)$.

Demographic and clinical characteristics of MCS recipients stratified according to sex are provided in Table 1 . Women were younger $(33.5 \%$ vs. $27.4 \%$ <age $50, \mathrm{p}<0.001)$ and less likely to be white $(\mathrm{p}<0.001)$. Women also had less atrial fibrillation, coronary artery disease, coronary artery bypass grafting, and acute renal failure than men. A significantly higher percentage of women underwent simultaneous BiVAD, extracorporeal VAD, and extracorporeal membrane oxygenation (ECMO) support compared to men, who more frequently underwent durable LVAD placement. In-hospital outcomes stratified by sex are summarized in Table 2. Women with MCS had significantly more MAEs than men (64.8\% vs. $52.5 \%$, p <0.001) driven primarily by increased mortality ( $52.3 \%$ vs. $40.8 \%$, p $<0.001)$ and incident stroke $(25.2 \%$ vs. $18.6 \%, \mathrm{p}<0.001)$. There were no significant differences between men and women in major bleeding (33.3\% vs. $32.8 \%, \mathrm{p}=0.86)$ or device infection ( $2.6 \%$ vs. $2.6 \%, \mathrm{p}=0.99)$. Among surviving patients, women were less likely to be discharged home than men ( $26 \%$ vs. $41 \%, \mathrm{p}<0.001)$. Women had considerably shorter median length of stay than men overall (19 [7-46] vs. 28 [9-52], p<0.001), due to a higher mortality in women and shorter length of stay in women who died (11 [4-28]) versus men who died (14 [5-36] days, $\mathrm{p}=0.005)$ compared to those who survived (33 [15-58] vs. 36 [20-59] days, $\mathrm{p}=0.052$ ). Annual trends in primary and secondary outcomes according to sex are summarized in Figure 2. Rates of MAE and death decreased considerably during the study period with a marked drop between 2007 and 2009, coinciding with the introduction of the continuous-flow LVAD device. Women had higher rates of MAEs and death, lower rates of discharge to home, and shorter length of stay at nearly every time point. 
Hospitalizations with MCS placement in non-INTERMACS participants resulted in transfer to another acute care hospital $(315 / 2,620,10.7 \%)$ significantly more frequently than INTERMACS participants $(20 / 1338,1.5 \%, \mathrm{p}<0.001)$.

\section{Multivariable Analysis}

Results of multivariable analysis for primary and secondary outcomes are found in Figures 3a-d. Multivariable logistic regression showed that female sex (OR 1.68, 95\% CI 1.41-1.92; $\mathrm{p}<0.001$ ) was associated with slightly higher odds of MAEs and death than patients who are $\checkmark 60$ years of age (OR 1.61, 95\% CI 1.35-1.92, p<0.001), even when adjusted for comorbidities, types of device, insurance status, year of procedure, and source of admission. Female sex was also associated with an increased risk of stroke (OR 1.41, 95\% CI 1.15$1.71, \mathrm{p}<0.001)$ adjusted for the same covariates, although traditional stroke risk factors were not ( $p>0.05$ for age $\geq 60$, atrial fibrillation, hypertension, and diabetes mellitus). Patients with temporary external MCS (OR 2.42, 95\% CI 1.24-4.72, p<0.001) and extracorporeal membrane oxygenation (ECMO) (OR 2.43, 95\% CI 1.48-4.02, p<0.001) were at highest risk of MAE and patients with acute renal failure (OR 2.47, 95\% CI 2.10-2.91, p<0.001) and ECMO (OR 2.93, 95\% CI 1.81-4.75, p<0.001) were at highest risk of death. Women were more likely to have a shorter length of stay in patients who died (incident rate [IR] $0.85,95 \%$ CI $0.83-0.87, p<0.001)$ and slightly longer length of stay in those who survived to discharge (IR $1.03,95 \%$ CI 1.01-1.04, $\mathrm{p}=0.002$ ). Among surviving patients, female sex (OR $0.58,95 \%$ CI $0.45-0.74, \mathrm{p}<0.001$ ) was associated with the lowest odds of discharge to home of any covariate tested except acute MI (OR 0.57, 95\% CI 0.44-0.76, p<0.001). INTERMACS participation was associated with lower likelihood of MAE (OR 0.54, 95\% 0.46-0.63, p<0.001) and in-hospital death (OR 0.48, 95\% CI 0.41-0.57 p<0.001). INTERMACS participation had a lower likelihood of a routine discharge home (OR 0.73, 95\% 0.61-0.89, $\mathrm{p}=0.001$ ) but a higher likelihood of discharge with home health (OR 3.29, $95 \% 2.69-4.04, \mathrm{p}<0.001$. In contrast, non-INTERMACS participants were much more likely to transfer patients to another hospital (OR 6.23, 95\% CI 3.73-10.4, p<0.001). Findings were similar if transfers to other hospitals were excluded.

\section{Device Selection}

Sex-specific trends in MAE associated with durable LVAD versus all other MCS and percentage of procedures utilizing MCS are shown in Figure 4a-c. Adjusted likelihood of MAE associated with durable LVAD placement was higher in women than men prior to 2007 (OR 2.01, 95\% CI 1.56-2.53, p<0.001) but not after 2007 (OR 1.47, 95\% CI 0.932.33, $\mathrm{p}=0.10$ ). Adjusted likelihood of MAE in all other types of MCS was not significantly different between men and women over the course of the study period both before $(\mathrm{p}=0.08)$ and after 2007 ( $\mathrm{p}=0.14)$. Adjusted likelihood of durable LVAD placement in women was lower than men throughout the study period (OR $0.63,95 \%$ CI $0.53-0.76, \mathrm{p}<0.001)$. This likelihood was lower after the introduction of continuous flow devices in 2007 (OR 0.45, $95 \% 0.30-0.67, \mathrm{p}<0.001$ ) compared with prior (OR 0.72, 95\% 0.60-0.86, $\mathrm{p}<0.001)$. These likelihoods were similar in both INTERMACS and non-INTERMACS participants. However, likelihood of durable LVAD use was higher in INTERMACS participants $(1,132 / 1383,81.9 \%)$ than non-INTERMACS participants $(1,861 / 2,954,63.0 \%, \mathrm{p}<0.001)$ throughout the study period (adjusted OR 2.80, 95\% CI 2.32-3.37, $\mathrm{p}<0.001$ ). There was no 
significant interaction between INTERMACS participation and likelihood of durable LVAD selection between men and women.

\section{DISCUSSION}

Our study is the largest to report sex differences for in-hospital outcomes in patients with MCS. This study included 1,383 patients from 45 participating INTERMACS sites and 2,954 patients from 246 non-INTERMACS sites, comprising the largest cohort of nonINTERMACS studied to date. Importantly, this includes MCS centers less likely to implant durable LVADs than INTERMACS participants. We found that baseline characteristics of women receiving MCS were significantly different than men. Although in-hospital outcomes at the time of MCS placement improved over time, women had higher rates and multivariable-adjusted likelihood of MAE and in-hospital mortality. Women were less likely to be discharged home than men, despite women being generally younger with fewer chronic comorbidities. Differences in outcomes seemed driven by higher adjusted likelihood of MAE in women prior to the introduction of continuous-flow devices around 2007, and a lower likelihood of durable LVAD placement in women throughout the study that which appeared to decrease further after 2007. These findings suggest that sex differences in clinical cardiovascular outcomes including heart failure (HF) patients undergoing MCS are influenced by differences in disease etiology, care delivery and utilization, disease progression, and biologic response to the same therapy.(7) The magnitude of difference in acute outcomes of MCS placement between men and women in this study suggests that additional research to determine the contributions of each of these factors, particularly with respect to device selection, is warranted.

Several studies have reported similar survival rates for men and women undergoing durable MCS. In an analysis of 465 bridge-to-transplant patients enrolled in the HeartMate II clinical trial who were followed for 18 months, the authors found similar survival rates between women and men.(17) For MAE, women had more hemorrhagic strokes and fewer devicerelated infections than men. Similarly, in an analysis of 332 patients enrolled in the ADVANCE BTT and continued access protocol trial, the investigators found similar survival rates between men and women.(18) In an analysis of 1,936 patients in INTERMACS, there were no statistically significant sex differences in survival for either pulsatile or continuousflow devices.(19) Our analysis incorporates data for all MCS—durable and extracorporeal. Despite some limitations, hospital administrative data allow for capture of significantly more patients than either clinical trials or registries.

\section{Sex Differences in Utilization of MCS}

A minority of MCS patients in this analysis were women. Our findings are consistent with MCS trial and registry data that show women make up a smaller percentage of VAD patients. $(8,20-22)$ This disparity has been noted in previous analyses of heart transplantation recipients as well.(23-25) Our findings suggest that women are less likely to undergo durable LVAD, although the reasons are not entirely clear. This disparity is likely due to a combination of factors. 
First, it is well established that men are more likely to have HF with systolic dysfunction than women, who are more likely to have HF with preserved ejection fraction. Consequently, patients with advanced HF and reduced ejection fraction are more often male by a margin of nearly 3:1.(26,27) Women make up a lower percentage of ischemic cardiomyopathy, which is one of the most common indications for MCS. $(27,28)$ Our results show that women were less likely than men to receive a durable LVAD alone and more likely to receive a simultaneous BiVAD or extracorporeal VAD. Further, among people under the age of 50 with a myocardial infarction (MI), women have a mortality rate twice as high as men.(29) Therefore, it is also possible that women die before being considered for MCS.

Second, the risk to benefit ratio of MCS in women is somewhat less clear than men.(19) Our findings are concordant with recent studies, which have suggested that women and men have similar outcomes following implantation of continuous-flow LVADs,(30) but it has also been proposed that patient selection bias has persisted following early observations of worse outcomes in women using pulsatile devices. Perhaps more importantly, it was reported that women referred for transplantation often have more advanced HF than men.(24) This disparity may exist because of sex differences in referral patterns. Indeed, if women are referred later, right ventricular dysfunction may be more common and explain increased use of BiVADs, which are usually non-durable MCS devices. Notably, women with HF are less likely to be referred to a cardiologist and more likely to be managed by their primary care physician irrespective of severity of illness.(31) In the present analysis, women appeared be younger and have fewer comorbidities overall than men, but severity of HF at presentation could not be assessed.

Third, it is possible that patient preference plays an important role. In general, women are more likely to have a do-not-resuscitate order than men.(32) One study showed no evidence of sex bias in selection of heart transplantation recipients, but women were more likely to refuse heart transplantation than men (29\% vs 9\%).(23) Further, women's smaller body habitus prohibited use of the larger, fully implantable devices available in the 1990s and early 2000s and may explain increased use of extracorporeal VADs in women. Even with the introduction of smaller, durable MCS, body image issues may be more prevalent in women and could influence their decision to pursue MCS.(33)

\section{Sex Differences in Outcomes of MCS}

Based on our study, women consistently demonstrate worse outcomes at the time of MCS implantation than men overall. Prior to 2007, this was primarily driven by differences in durable LVAD outcomes when adjusted for other major patient factors, whereas the difference after 2007 seems to be driven by sex differences in device selection with men being more likely to undergo durable LVAD. These trends suggest a strong component of device selection in explaining these sex differences. One possible explanation could be that women present later in the disease process when they are more acutely ill, which could affect device selection. $(19,34)$ In the present study, women and men were equally likely to present with acute MI or cardiogenic shock, and men were more likely to present with acute renal failure, suggesting that women were not substantially more acutely ill than men. 
As prior studies have shown, there was a significantly higher rate of stroke reported in women in the present study, driven by a greater than two-fold difference after 2008 compared to a 1.2-fold difference prior to 2008. Notably, strokes have been shown to be equally as common with pulsatile and continuous-flow LVADs.(35) In a recent analysis of patients with durable LVADs, female sex was a risk factor for both hemorrhagic and ischemic stroke.(36) Given existing literature and our data, which support that association, there may be a physiologic reason women are more likely to experience a stroke following MCS implantation that has not been identified

Final disposition and length of stay were also significantly different in women, consistent with less favorable outcomes. Women had a shorter length of stay driven primarily by higher in-hospital mortality and shorter length of stay in women who died-meaning when women died in the hospital, they died rapidly. Women who survived were less likely to be discharged home than male survivors and instead were more likely to be transferred to another facility or discharged to a skilled nursing facility. As stated above, women are often acutely ill on presentation. $(19,34)$ Therefore they may be more likely to be transferred to a higher level of care although there were no significant sex differences in likelihood of transfer, admission source, or rate of MI or shock in this study. Further study of metrics including frailty or severity of HF at presentation may help define why women were more likely to need ongoing care in a skilled nursing facility. Finally it is possible that women are less likely than men to have a caregiver or to have the resources required of a MCS recipient. $(37,38)$

Sex disparities with MCS remain poorly understood. Based on projections, the prevalence of HF will continue to rise.(39) Future research should be focused on why disparities exist between women and men receiving MCS, particularly with respect to differences in acute outcomes and device selection in patients undergoing MCS implantation. A recent perspective piece discusses sex differences in mortality and outcomes for patients with HF, MCS, and heart transplantation.(25) The consensus is to urge researchers to understand the disparities, specifically sex related, in the delivery of care for advanced HF. Further data are needed to help understand these disparities and find ways to provide equivalent care to women.

\section{Limitations}

Our study had several limitations. First, this is a claims-based study including unidentified confounders, misclassification, and missing data due to state administrative procedures for de-identification. Every effort was made to account for this, including multivariable analysis. Second, because of the de-identification process, destination hospital in transfer patients and outcomes following discharge from the index hospitalization could not be assessed. Third, details regarding the device implanted were not available. Specifically it was not possible to determine whether pulsatile or continuous-flow devices were used in a given procedure. Lastly, patient-level information such as medications, hemodynamics, ejection fraction, and lab values were not available; therefore, patient acuity at the time of MCS placement could not be determined. 


\section{CONCLUSION}

Our analysis reaffirms that women are less likely to receive MCS than men. Despite accounting for age and other comorbidities, women undergoing MCS experience more MAEs and higher in-hospital mortality than men. The reasons for these sex differences are multifactorial, and further research is warranted.

\section{REFERENCES}

1. Kirklin JW, Donald DE, Harshbarger HG, et al. Studies in extracorporeal circulation. I. Applicability of Gibbon-type pump-oxygenator to human intracardiac surgery: 40 cases. Ann Surg.1956;144:2-8. [PubMed: 13327835]

2. Liotta D, Hall CW, Henly WS, Cooley DA, Crawford ES, Debakey ME. Prolonged Assisted Circulation during and after Cardiac or Aortic Surgery. Prolonged Partial Left Ventricular Bypass by Means of Intracorporeal Circulation. Am J Cardiol. 1963;12:399-405. [PubMed: 14064861]

3. Hogue CW Jr., Barzilai B, Pieper KS et al. Sex differences in neurological outcomes and mortality after cardiac surgery: a society of thoracic surgery national database report. Circulation. 2001;103:2133-7. [PubMed: 11331252]

4. Vaccarino V, Abramson JL, Veledar E, Weintraub WS. Sex differences in hospital mortality after coronary artery bypass surgery: evidence for a higher mortality in younger women. Circulation. 2002;105:1176-81. [PubMed: 11889010]

5. Edwards FH, Carey JS, Grover FL, Bero JW, Hartz RS. Impact of gender on coronary bypass operative mortality. Ann Thorac Surg. 1998;66:125-31. [PubMed: 9692451]

6. Stretch R, Sauer CM, Yuh DD, Bonde P. National trends in the utilization of short-term mechanical circulatory support: incidence, outcomes, and cost analysis. J Am Coll Cardiol. 2014;64:1407-15. [PubMed: 25277608]

7. Stulak JM, Deo S, Cowger J et al. Do Racial and Sex Disparities Exist in Clinical Characteristics and Outcomes for Patients Undergoing Left Ventricular Assist Device Implantation? The Journal of Heart and Lung Transplantation;32:S279-S280.

8. Kirklin JK, Naftel DC, Pagani FD et al. Seventh INTERMACS annual report: 15,000 patients and counting. J Heart Lung Transplant. 2015;34:1495-504. [PubMed: 26520247]

9. Interagency Registry for Mechanically Assisted Circulatory Support (INTERMACS). Available from: http://www.uab.edu/medicine/intermacs/. Accessed 21 April 2015.

10. California Office of Statewide Health Planning and Development. Available from: http:// www.oshpd.ca.gov/HID/Products/PatDischargeData/PublicDataSet/index.html. Accessed 20 March 2015.

11. Statewide Planning and Research Cooperative System (SPARCS). Department of Health, New York State Available from: http://www.health.ny.gov/statistics/sparcs/. Accessed 16 August 2015.

12. Office of Health Care Quality Assessment, New Jersey Department of Health. Available from: http://www.state.nj.us/health/healthcarequality/ub/ub92intro.shtml. Accessed 21 March 2015.

13. Hospital Discharge Data. New Hampshire Department of Health and Human Services. Available from: http://www.dhhs.nh.gov/dphs/hsdm/requests.htm. Accessed 21 March 2015.

14. West Virginia hospital discharge data. West Virginia Health Care Authority. Available from: http:// www.hca.wv.gov/data/requestdata/Pages/default.aspx. Accessed 21 March 2015.

15. Colorado Hospital Association. Hospital Discharge Data. Available from: http://www.cha.com/. Accessed 20 March 2015.

16. Texas Department of State Health Services. Hospital Discharge Data Public Use Data Files. Available from: https://www.dshs.state.tx.us/THCIC/Hospitals/Download.shtm. Accessed 28 June 2015.

17. Bogaev RC, Pamboukian SV, Moore SA et al. Comparison of outcomes in women versus men using a continuous-flow left ventricular assist device as a bridge to transplantation. J Heart Lung Transplant. 2011;30:515-22. [PubMed: 21257321] 
18. Birks EJ, McGee EC Jr., Aaronson KD et al. An examination of survival by sex and race in the HeartWare Ventricular Assist Device for the Treatment of Advanced Heart Failure (ADVANCE) Bridge to Transplant (BTT) and continued access protocol trials. J Heart Lung Transplant. 2015;34:815-24. [PubMed: 25813372]

19. Hsich EM, Naftel DC, Myers SL et al. Should women receive left ventricular assist device support?: findings from INTERMACS. Circ Heart Fail. 2012;5:234-40. [PubMed: 22260946]

20. Pagani FD, Miller LW, Russell SD et al. Extended mechanical circulatory support with a continuous-flow rotary left ventricular assist device. J Am Coll Cardiol. 2009;54:312-21. [PubMed: 19608028]

21. Aaronson KD, Slaughter MS, Miller LW et al. Use of an intrapericardial, continuous-flow, centrifugal pump in patients awaiting heart transplantation. Circulation. 2012;125:3191-200. [PubMed: 22619284]

22. Slaughter MS, Rogers JG, Milano CA et al. Advanced heart failure treated with continuous-flow left ventricular assist device. N Engl J Med. 2009;361:2241-51. [PubMed: 19920051]

23. Aaronson KD, Schwartz JS, Goin JE, Mancini DM. Sex differences in patient acceptance of cardiac transplant candidacy. Circulation. 1995;91:2753-61. [PubMed: 7758181]

24. Regitz-Zagrosek V, Petrov G, Lehmkuhl E et al. Heart transplantation in women with dilated cardiomyopathy. Transplantation. 2010;89:236-44. [PubMed: 20098289]

25. Cook JL, Grady KL, Colvin M et al. Sex differences in the care of patients with advanced heart failure. Circ Cardiovasc Qual Outcomes. 2015;8:S56-9. [PubMed: 25714825]

26. Hsich EM, Grau-Sepulveda MV, Hernandez AF et al. Sex differences in in-hospital mortality in acute decompensated heart failure with reduced and preserved ejection fraction. Am Heart J. 2012;163:430-7, 437 e1-3. [PubMed: 22424014]

27. Ghali JK, Krause-Steinrauf HJ, Adams KF et al. Gender differences in advanced heart failure: insights from the BEST study. J Am Coll Cardiol. 2003;42:2128-34. [PubMed: 14680739]

28. Simon T, Mary-Krause M, Funck-Brentano C, Jaillon P. Sex differences in the prognosis of congestive heart failure: results from the Cardiac Insufficiency Bisoprolol Study (CIBIS II). Circulation. 2001;103:375-80. [PubMed: 11157688]

29. Vaccarino V, Parsons L, Every NR, Barron HV, Krumholz HM. Sex-based differences in early mortality after myocardial infarction. National Registry of Myocardial Infarction 2 Participants. N Engl J Med. 1999;341:217-25. [PubMed: 10413733]

30. Tsiouris A, Morgan JA, Nemeh HW, Hodari A, Brewer RJ, Paone G. Sex-specific outcomes in patients receiving continuous-flow left ventricular devices as a bridge to transplantation or destination therapy. ASAIO J. 2014;60:199-206. [PubMed: 24577371]

31. Petrie MC, Dawson NF, Murdoch DR, Davie AP, McMurray JJ. Failure of women's hearts. Circulation. 1999;99:2334-41. [PubMed: 10226101]

32. Wenger NS, Pearson ML, Desmond KA et al. Epidemiology of do-not-resuscitate orders. Disparity by age, diagnosis, gender, race, and functional impairment. Arch Intern Med. 1995;155:2056-62. [PubMed: 7575064]

33. Marcuccilli L, Casida JJ. Overcoming alterations in body image imposed by the left ventricular assist device: a case report. Prog Transplant. 2012;22:212-6. [PubMed: 22878080]

34. Guru V, Fremes SE, Austin PC, Blackstone EH, Tu JV. Gender differences in outcomes after hospital discharge from coronary artery bypass grafting. Circulation. 2006;113:507-16. [PubMed: 16449730]

35. Starling RC, Naka Y, Boyle AJ et al. Results of the post-U.S. Food and Drug Administrationapproval study with a continuous flow left ventricular assist device as a bridge to heart transplantation: a prospective study using the INTERMACS (Interagency Registry for Mechanically Assisted Circulatory Support). J Am Coll Cardiol. 2011;57:1890-8. [PubMed: 21545946]

36. Boyle AJ, Jorde UP, Sun B et al. Pre-operative risk factors of bleeding and stroke during left ventricular assist device support: an analysis of more than 900 HeartMate II outpatients. J Am Coll Cardiol. 2014;63:880-8. [PubMed: 24316083] 
37. Cook JL, Grady KL, Colvin M, Joseph SM, Brisco MA, Walsh MN. Sex differences in the care of patients with advanced heart failure. Circ Cardiovasc Qual Outcomes. 2015;8:S56-9. [PubMed: 25714825]

38. Farran CJ. Family caregiver intervention reseach: where have we been? Where are we going? J Gerontol Nurs. 2001;27:38-45.

39. Mozaffarian D, Benjamin EJ, Go AS et al. Heart disease and stroke statistics-2015 update: a report from the american heart association. Circulation. 2015;131:e29-e322. [PubMed: 25520374] 


\section{Gender distribution over time for MCS and OHT}

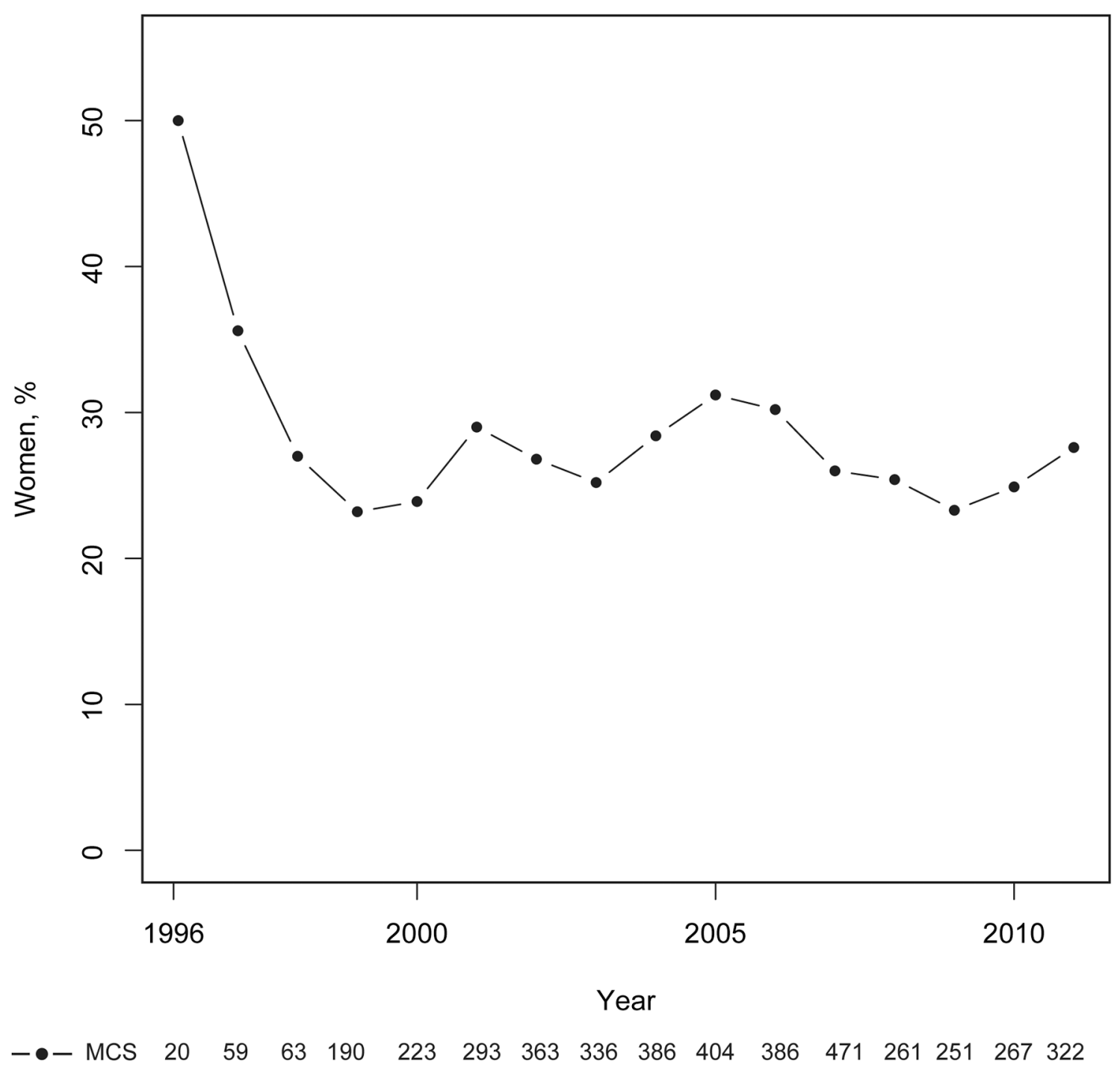

Figure 1.

Sex Trends in MCS Over Time 
Rate of major adverse events over time by gender

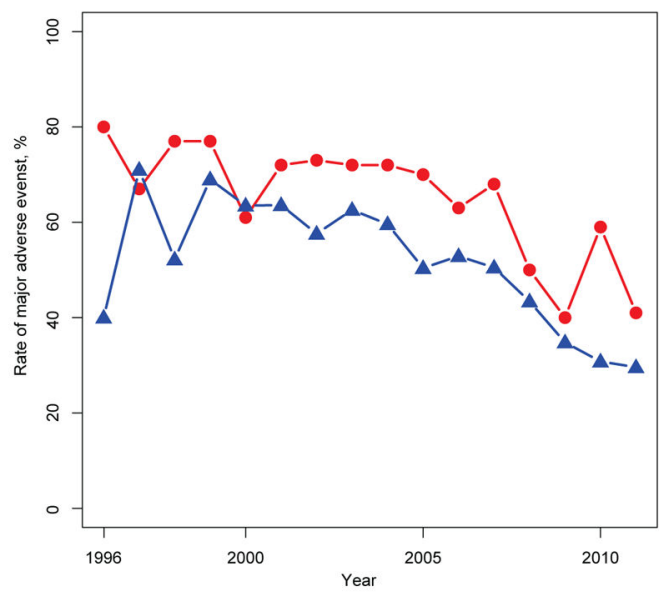

$-\Delta-$ Men

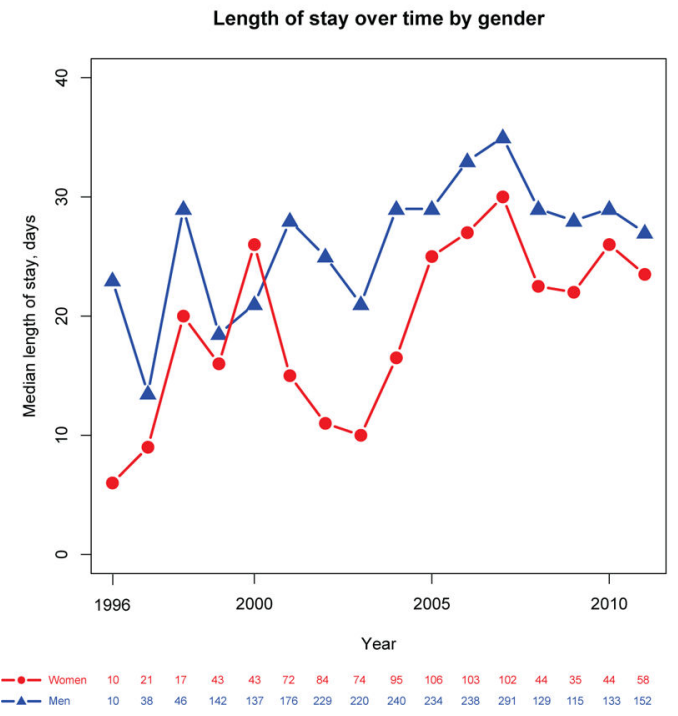

In-hospital death rates over time by gender

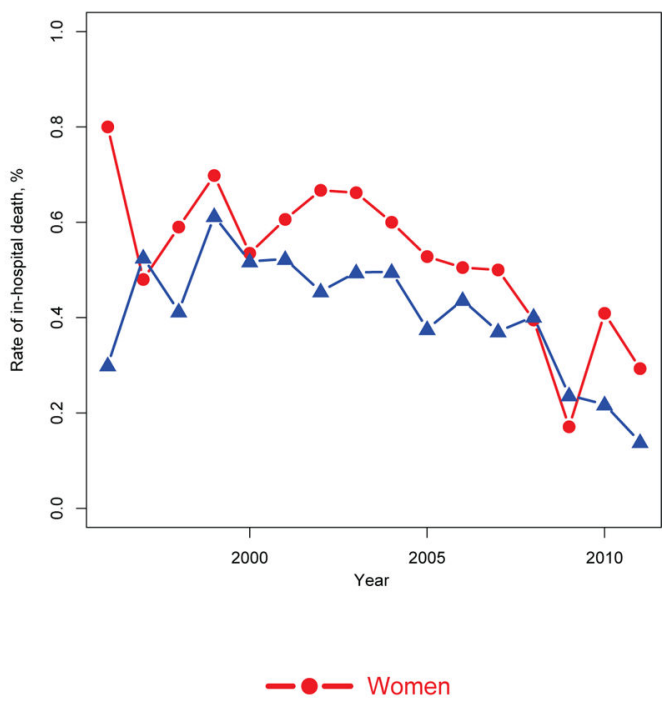

Rate of discharge to home over time by gender

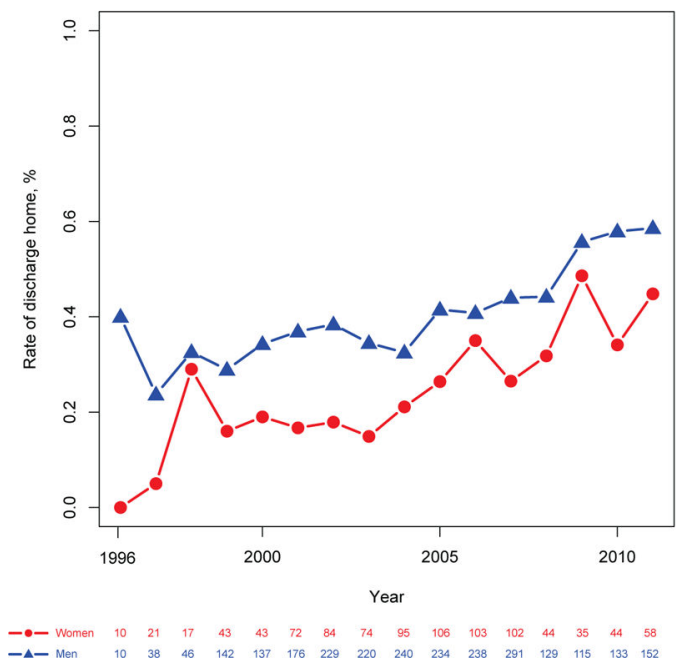

Figure 2.

Trends in Major Adverse Events, Death, Length of Stay, and Discharge to Home at time of Mechanical Circulatory Support Placement According to Sex 
Multivariate predictors of major adverse events

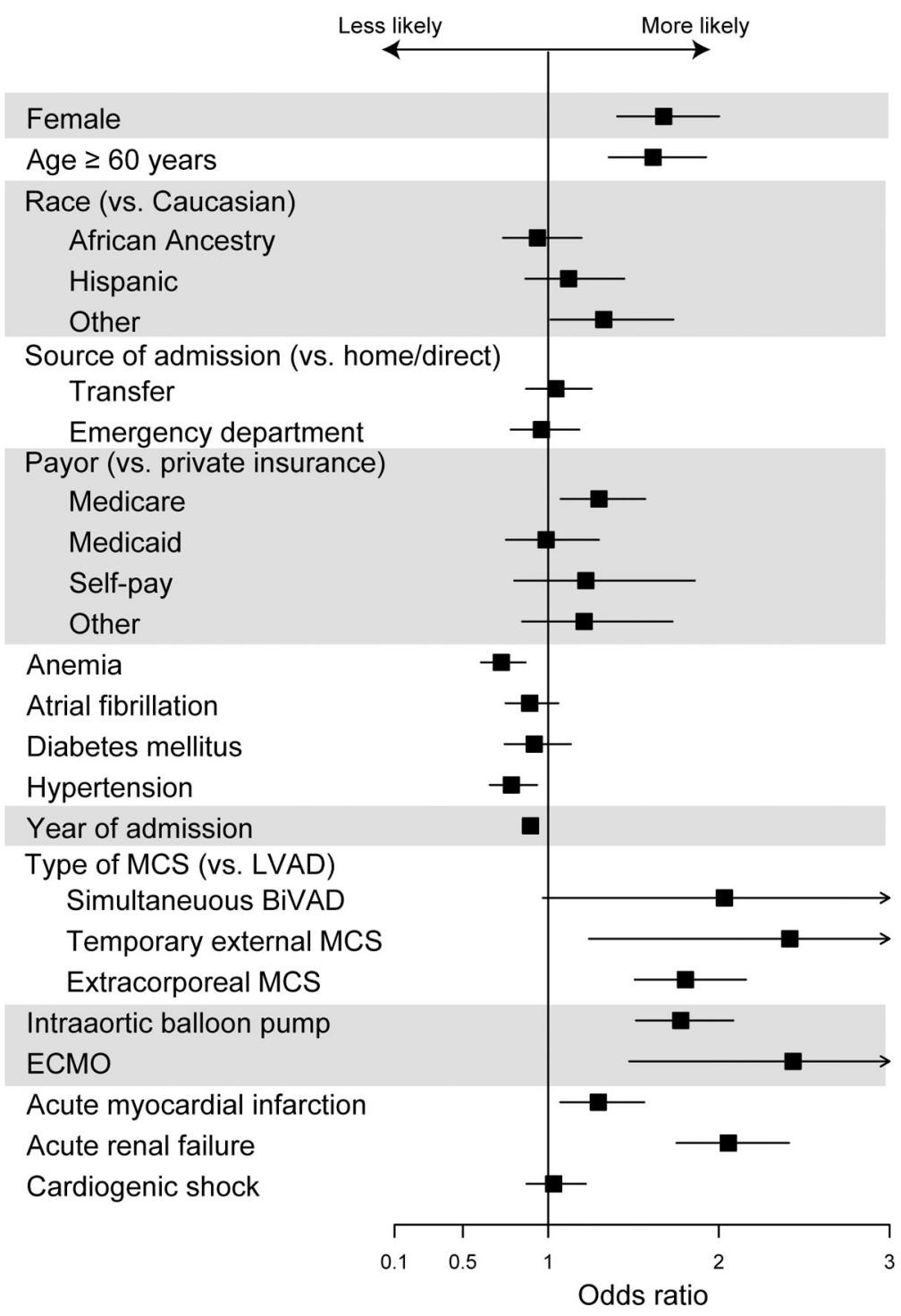

Figure 3a.

Multivariate Odds of Major Adverse Events Associated with Mechanical Circulatory Support Placement 


\section{Multivariate predictors of death}

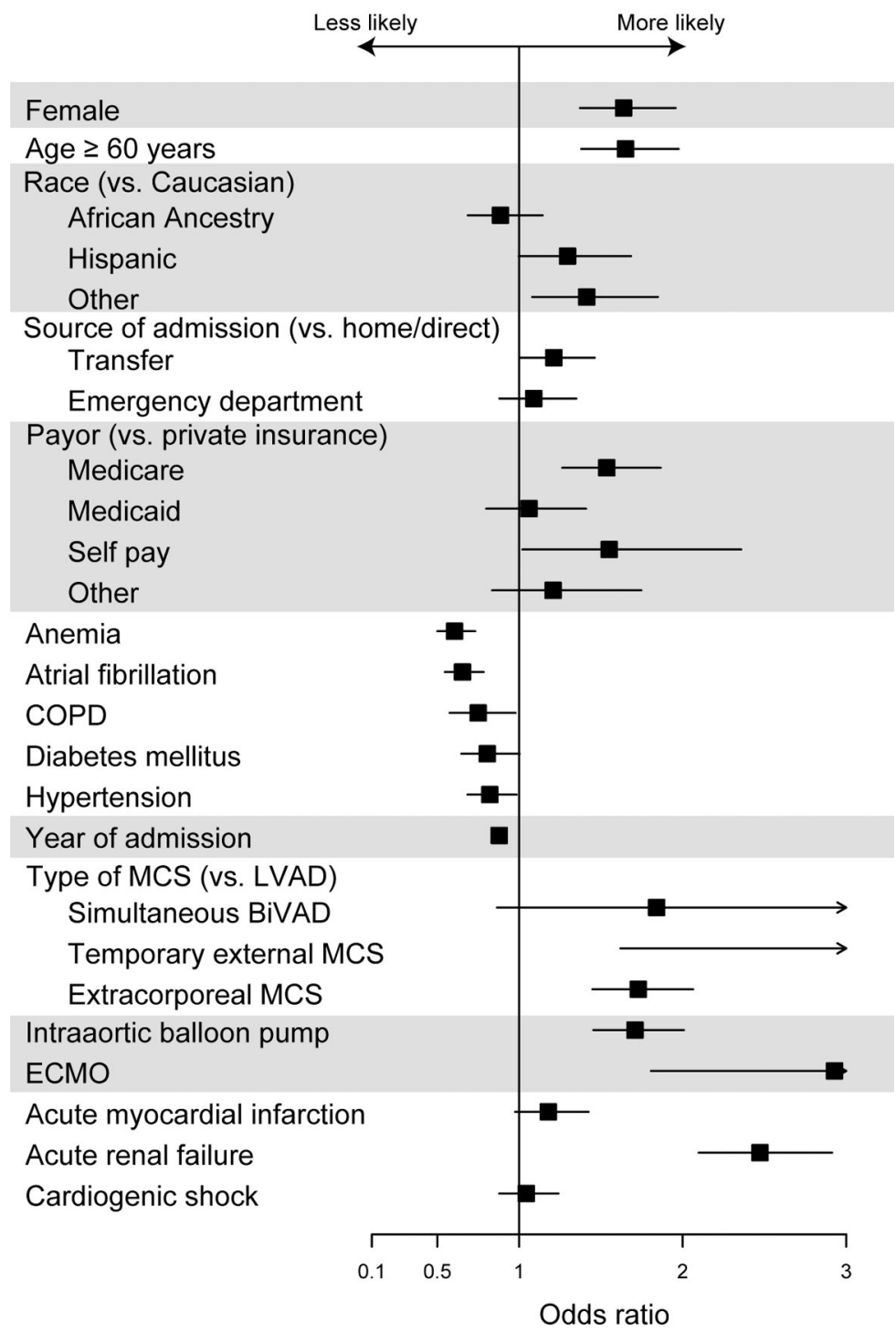

Figure 3b.

Multivariate Predictors of Death 


\section{Multivariate predictors of length of stay}

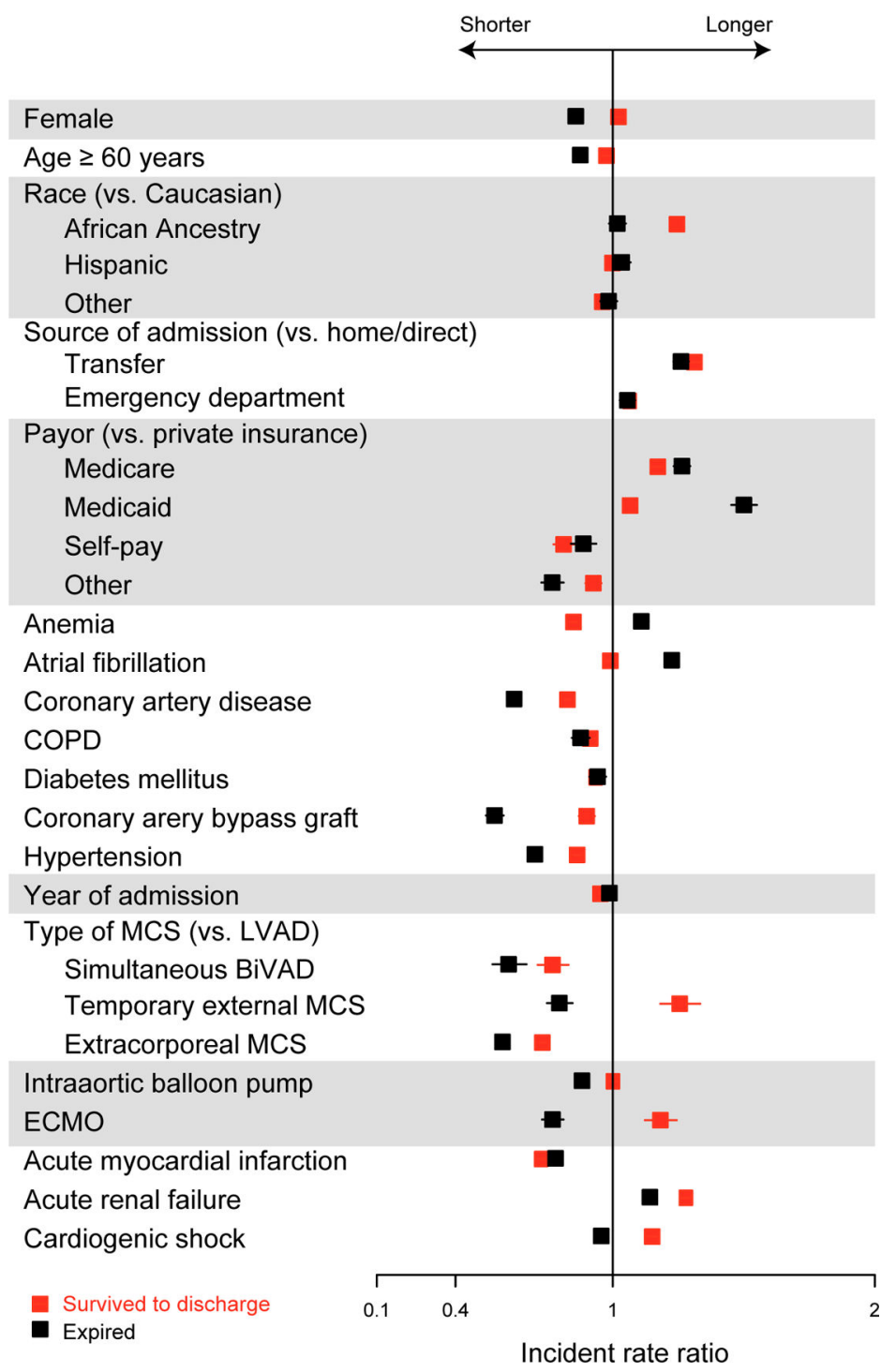

Figure 3c.

Multivariate Predictors of Length of Stay 


\section{Multivariate predictors of discharge home among survivors}

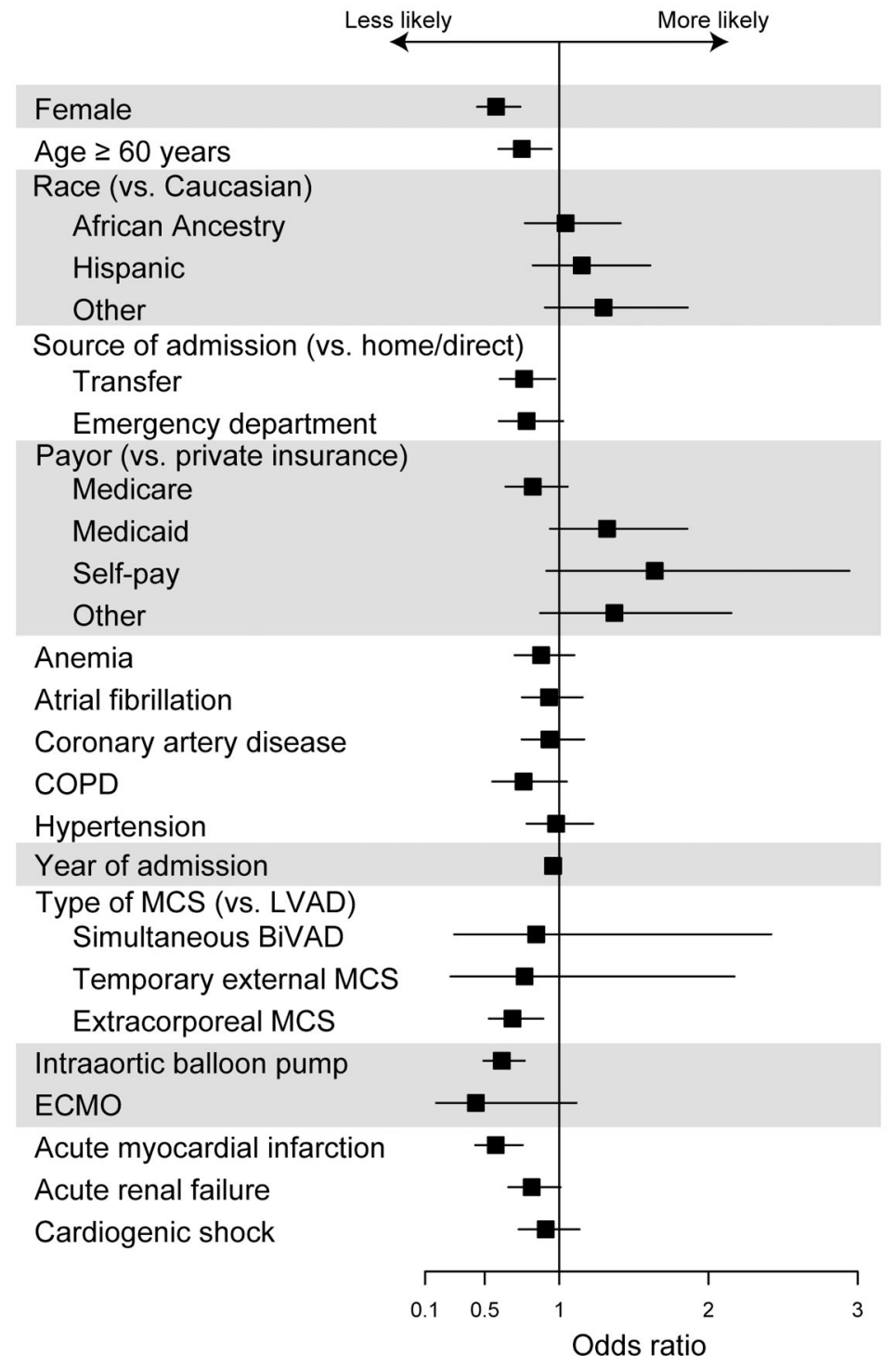

Figure 3d.

Multivariate Predictors of Discharge Home Among Survivors 
MAE rates over time by gender, implantable VAD only

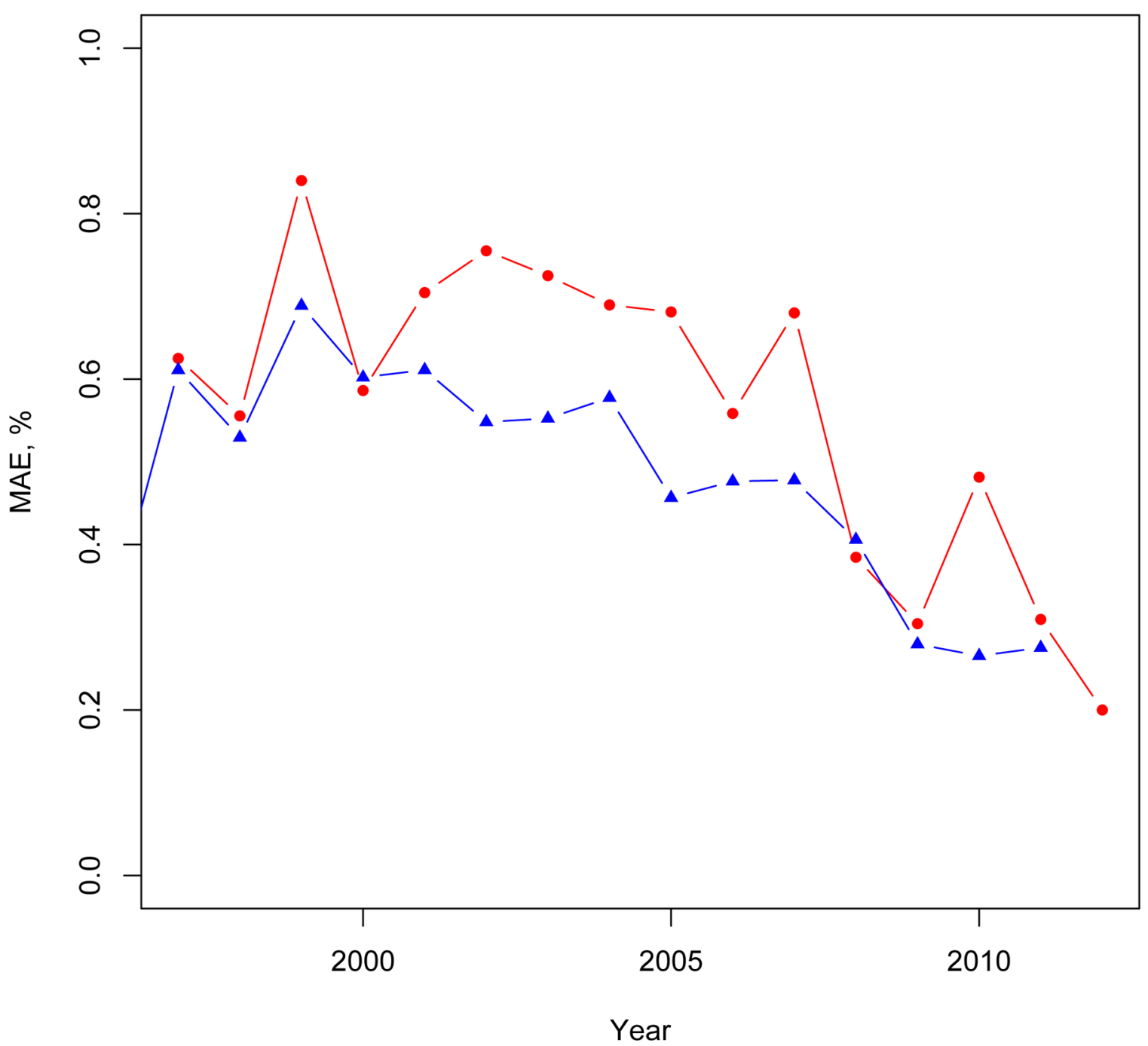

Figure 4a.

Major Adverse Event trends, Durable VAD only 
MAE rates over time by gender, all other VADs

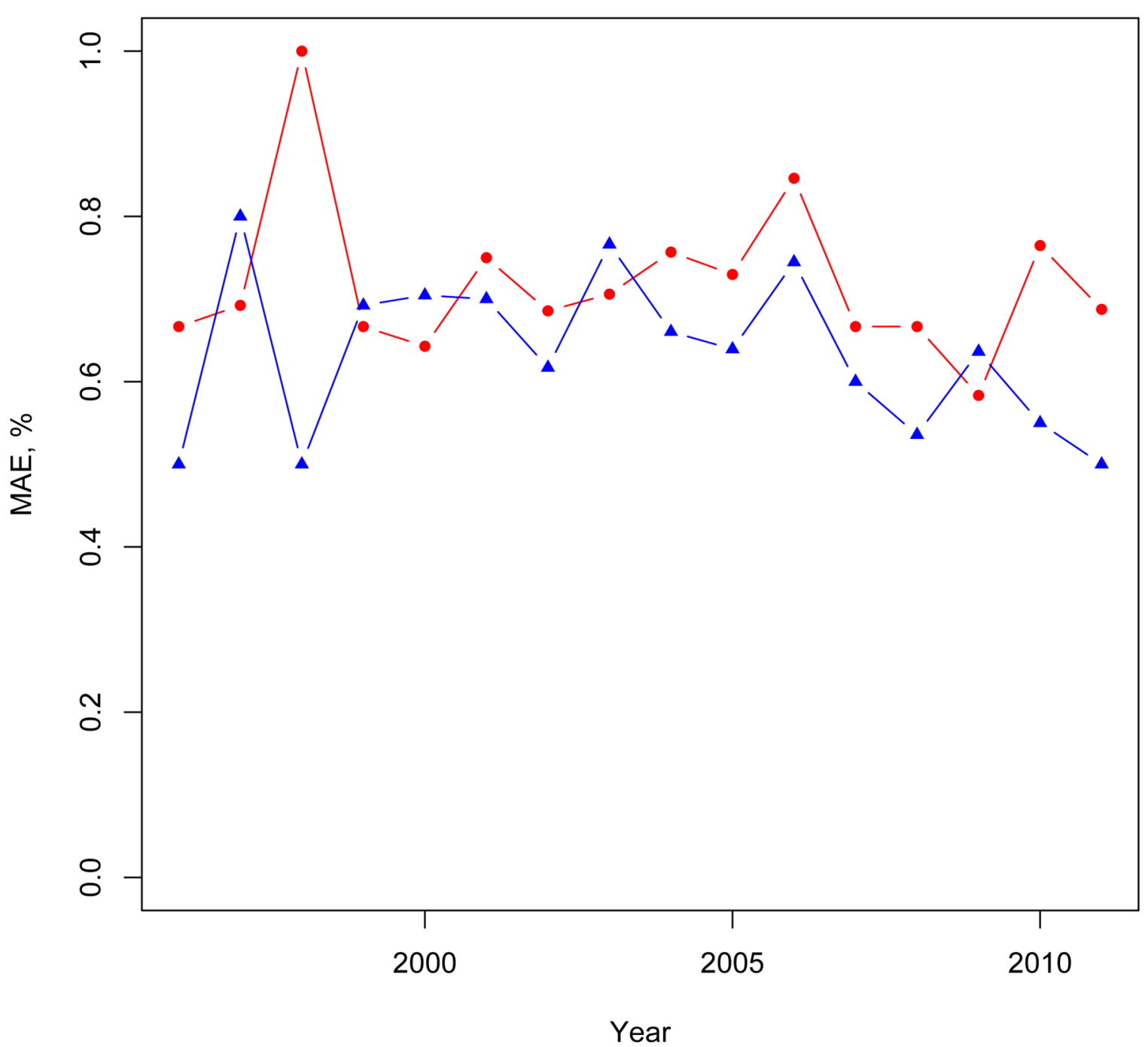

Figure 4b.

Major Adverse Event trends, All Other MCS 
Durable VAD distribution over time by gender

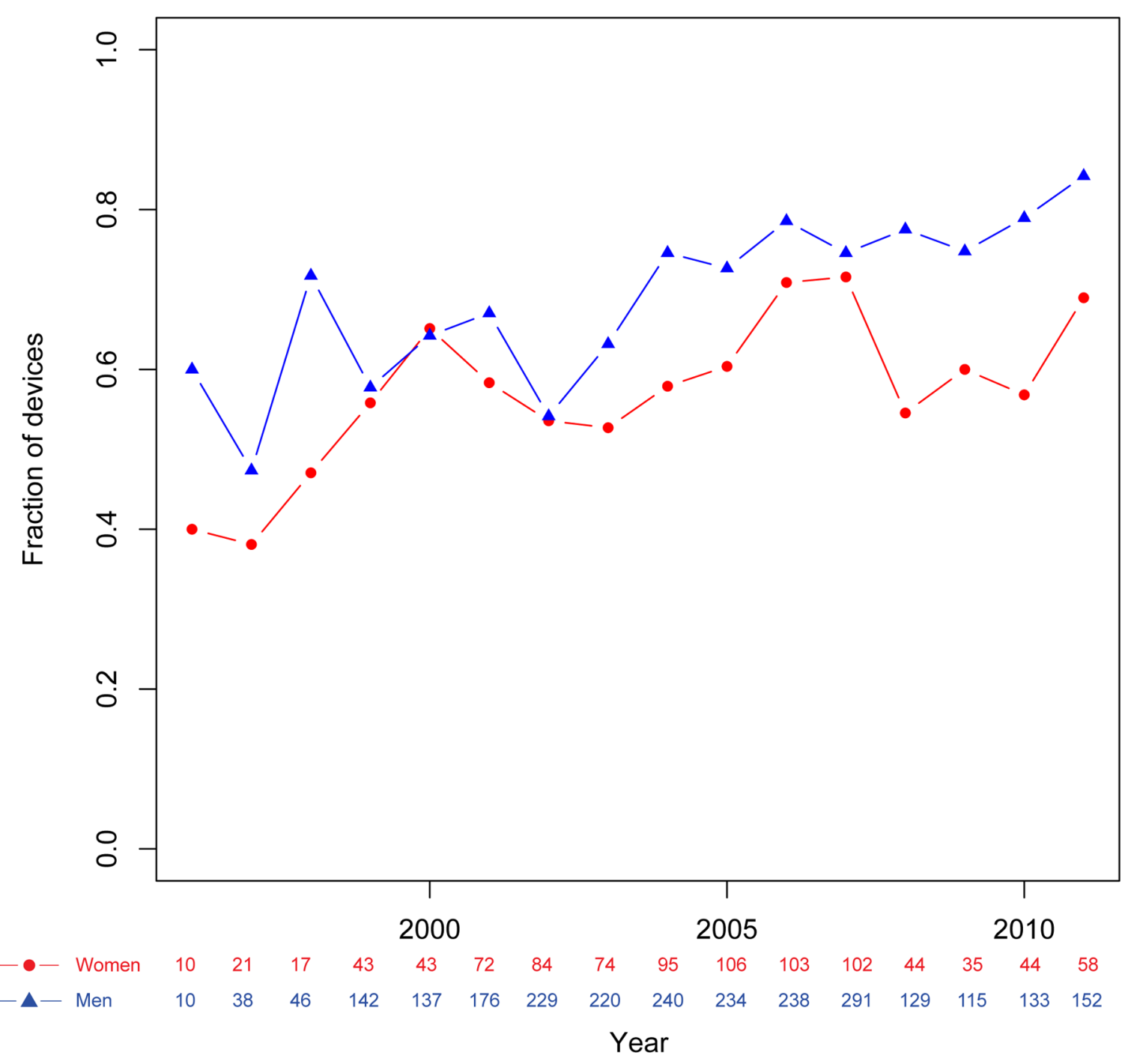

Figure 4c.

Trends of Durable VAD Use by Sex 
Table 1.

Patient Characteristics, Mechanical Circulatory Support Patients, N (\%)

\begin{tabular}{|c|c|c|c|c|c|}
\hline Characteristic & $\begin{array}{c}\text { All } \\
4337\end{array}$ & $\begin{array}{c}\text { Men } \\
2558(59)\end{array}$ & $\begin{array}{l}\text { Women } \\
965(22)\end{array}$ & $\begin{array}{l}\text { M vs. W } \\
\text { p-value }\end{array}$ & $\begin{array}{l}\text { Sex NA } \\
814 \text { (19) }\end{array}$ \\
\hline Age, yrs & & & & $<0.001$ & \\
\hline $18-29$ & $151(3)$ & $82(3)$ & $64(7)$ & & $5(1)$ \\
\hline $30-39$ & $239(6)$ & $137(5)$ & $81(8)$ & & $21(3)$ \\
\hline $40-49$ & $584(13)$ & $416(16)$ & $143(15)$ & & $25(3)$ \\
\hline $50-59$ & $1053(24)$ & $776(30)$ & $245(25)$ & & $32(4)$ \\
\hline $60-69$ & $1071(25)$ & $768(30)$ & $255(26)$ & & $48(6)$ \\
\hline$>70$ & $550(13)$ & $366(14)$ & $169(18)$ & & $15(2)$ \\
\hline NA & $689(16)$ & $13(1)$ & $8(1)$ & & $668(82)$ \\
\hline Race & & & & $<0.001$ & \\
\hline Caucasian & $2129(49)$ & $1579(62)$ & $539(56)$ & & $11(1)$ \\
\hline African Ancestry & $413(10)$ & $265(10)$ & $139(14)$ & & $9(1)$ \\
\hline Hispanic & $366(8)$ & $242(9)$ & $112(12)$ & & $12(1)$ \\
\hline Other & $322(7)$ & $236(9)$ & $79(8)$ & & $7(1)$ \\
\hline NA & $1107(26)$ & $236(9)$ & $96(10)$ & & $775(95)$ \\
\hline Source of admission & & & & 0.81 & \\
\hline Home & $1701(39)$ & $1055(41)$ & $384(40)$ & & $262(32)$ \\
\hline Transfer & $1713(39)$ & $914(36)$ & $352(36)$ & & $447(55)$ \\
\hline ED & $899(21)$ & $573(22)$ & $221(23)$ & & $105(13)$ \\
\hline NA & $24(1)$ & $16(1)$ & $8(1)$ & & $0(0)$ \\
\hline Payor & & & & 0.02 & \\
\hline Medicare & $1521(35)$ & $914(36)$ & $364(38)$ & & $243(30)$ \\
\hline Medicaid & $496(11)$ & $246(10)$ & $116(12)$ & & $134(16)$ \\
\hline Private & $1946(45)$ & $1159(45)$ & $397(41)$ & & $390(48)$ \\
\hline Self-pay & $138(3)$ & $102(4)$ & $27(3)$ & & $9(1)$ \\
\hline Other & $203(5)$ & $114(4)$ & $54(6)$ & & $35(4)$ \\
\hline NA & $33(1)$ & $23(1)$ & $7(1)$ & & $3(0)$ \\
\hline \multicolumn{6}{|l|}{ Comorbidities } \\
\hline Anemia & $1223(28)$ & $625(24)$ & $267(28)$ & 0.049 & $331(41)$ \\
\hline Atrial fibrillation & $1279(29)$ & $772(30)$ & $235(24)$ & $<0.001$ & $272(33)$ \\
\hline Coronary artery disease & $1919(44)$ & $1200(47)$ & 377 (39) & $<0.001$ & $342(42)$ \\
\hline COPD & $476(11)$ & $264(10)$ & $101(10)$ & 0.9 & $111(14)$ \\
\hline Diabetes mellitus & $815(19)$ & $471(18)$ & $162(17)$ & 0.26 & $182(22)$ \\
\hline Coronary artery bypass graft & $274(6)$ & $167(7)$ & $36(4)$ & 0.001 & $71(9)$ \\
\hline Hypertension & $1393(32)$ & $768(30)$ & $299(31)$ & 0.58 & $326(40)$ \\
\hline Cardiogenic shock & $2310(53)$ & $1320(52)$ & $514(53)$ & 0.38 & $476(58)$ \\
\hline Acute myocardial infarction & $1246(29)$ & $762(30)$ & $311(32)$ & 0.16 & $173(21)$ \\
\hline Acute renal failure & 979 (39) & $1209(47)$ & $416(43)$ & 0.027 & $446(55)$ \\
\hline
\end{tabular}

J Heart Lung Transplant. Author manuscript; available in PMC 2020 March 09. 


\begin{tabular}{|c|c|c|c|c|c|}
\hline Characteristic & $\begin{array}{c}\text { All } \\
4337\end{array}$ & $\begin{array}{c}\text { Men } \\
2558 \text { (59) }\end{array}$ & $\begin{array}{c}\text { Women } \\
965(22)\end{array}$ & $\begin{array}{c}\text { M vs. W } \\
\text { p-value }\end{array}$ & $\begin{array}{l}\text { Sex NA } \\
814 \text { (19) }\end{array}$ \\
\hline LVAD & $3134(72)$ & $1893(74)$ & $616(64)$ & $<0.001$ & $625(77)$ \\
\hline Simultaneous BiVAD & $84(2)$ & $23(1)$ & $20(2)$ & 0.005 & $41(5)$ \\
\hline Intraaortic balloon pump & $1672(39)$ & $1051(41)$ & $380(39)$ & 0.36 & $241(30)$ \\
\hline Temporary VAD & $86(2)$ & $53(2)$ & $18(2)$ & 0.7 & $15(2)$ \\
\hline Extracorporeal VAD & $1195(28)$ & $689(27)$ & $347(36)$ & $<0.001$ & $159(20)$ \\
\hline ECMO & $186(4)$ & $69(3)$ & $42(4)$ & 0.01 & $75(5)$ \\
\hline
\end{tabular}

$\mathrm{BiVAD}=$ biventricular ventricular assist device, $\mathrm{COPD}=$ chronic obstructive pulmonary disease

$\mathrm{ED}=$ emergency department, $\mathrm{LVAD}=$ left ventricular assist device, $\mathrm{ECMO}=$ extracorporeal membrane oxygenation, $\mathrm{NA}=$ not applicable, $\mathrm{VAD}=$ ventricular assist device 
Table 2.

Patient Outcomes According to Sex, Mechanical Circulatory Support Patients, N (\%)

\begin{tabular}{rccccc} 
& All & Men & Women & M vs. W & NA \\
Characteristic & $\mathbf{4 3 3 7}$ & $\mathbf{2 5 5 8 ( 5 9 )}$ & $\mathbf{9 6 5 ( 2 2 )}$ & p-value & $\mathbf{8 1 4 ( 1 9 )}$ \\
\hline Outcomes & & & & & \\
$\quad \begin{array}{r}\text { Major adverse event } \\
\text { Length of stay, days }\end{array}$ & $2412(56)$ & $1344(53)$ & $625(65)$ & $<0.001$ & $544(54)$ \\
Disposition & & & & $<0.001$ & \\
Death & $1840(42)$ & $1042(41)$ & $505(52)$ & & $292(36)$ \\
Home & $1050(24)$ & $662(26)$ & $146(15)$ & & $242(30)$ \\
Home health & $653(15)$ & $388(15)$ & $106(11)$ & & $159(20)$ \\
Skilled nursing facility & $257(6)$ & $146(6)$ & $84(9)$ & & $29(4)$ \\
Transfer to acute hospital & $335(8)$ & $214(8)$ & $92(10)$ & & $65(8)$ \\
Other & $202(5)$ & $105(4)$ & $32(3)$ & & $<0.001$ \\
\hline
\end{tabular}

